\title{
Design and calculation of energy efficient windows of high-rise building
}

\author{
Aleksandr Konstantinov $^{1,}{ }^{*}$, Margarita Borisova $^{1}$, Maya Lambias Ratnayake ${ }^{1}$, and Tatyana \\ Arcibasova $^{1}$ \\ ${ }^{1}$ Moscow State University of Civil Engineering, 129337 Yaroslavskoe shosse, 26, Moscow, Russia
}

\begin{abstract}
The paper identifies the key issues concerning design and calculation of energy efficient windows of high-rise buildings that should be considered at the initial stages of a building design. The analysis of the functional and technical requirements which must be met by window structures in high-rise buildings was performed. The features of wind loads on the high-rise building windows were considered. The specificity of providing air- and water permeability of high-rise building windows under the action of high wind loads was considered. The conducted scientific research review on specific design and calculation issues of high-rise building windows was made. It is established that they are mainly aimed at finding optimal design solutions of the high-rise building windows in terms of energy efficiency. A similar situation is observed in the design of windows, when the issues of ensuring the strength and reliability of these structures are given less attention. It is established that at present, the strength calculation methods of fasteners and protective fences of windows are not developed; the excess stock is laid in the method of profile elements strength calculation, which is confirmed by the results of laboratory tests. The prospective scheme for calculating and appointing design solutions of high-rise buildings windows was presented, which provides an opportunity to ensure reliability, durability, and operational safety of high-rise building windows during all their life cycle. The paper specifies areas for further research of the matter under consideration.
\end{abstract}

\section{Introduction}

Over the past few years, the volume of construction of high-rise buildings and complexes in Russia and the world has increased significantly. This is especially evident in the increased number of high-rise buildings and apartments being built. A distinctive feature of such structures is the predominant use of glazed large-format window units (see figure 1), rather than translucent facades characteristic of high-rise public buildings (first of all, administrative and office centers). This is due to both modern architectural tendencies and, often, lower cost of manufacturing, installation and operation of window units in comparison with translucent facades.

\footnotetext{
* Corresponding author: apkonst@yandex.ru
} 


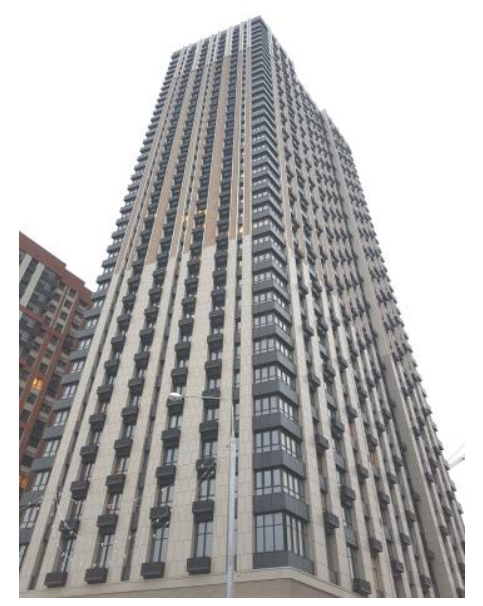

Fig. 1. The example of large-format window units in modern project of residential high-rise building

The high-rise building window design and calculation is much more complicated than similar structures used in multi-storey buildings with a height of less than $75 \mathrm{~m}$. First of all, this is due to the need for additional measures to ensure the safe operation and maintenance of high-rise building windows and high values of wind load on such buildings. Therefore, the purpose of this work is the review of the design problems of high-rise building windows, taking into account their loads and actions.

\title{
2 Technical requirements for high-rise building windows
}

The windows of high-rise buildings must meet the following technical and functional requirements $[1,2]$ :

- providing natural light and insolation of premises;

- providing thermal protection in the building and normal temperature and humidity conditions within the premises;

- protection against external noise (soundproofing);

- the lack of ventilation and leakage (air- and water-permeability of windows);

- bearing all loads and impacts acting on the window (own weight, wind load, operational loads, temperature loads) without excessive deformation and destruction of the window as a whole and its separate elements (for example, insulating glass unit, fastening elements, etc.);

- manufacturability and ease of installation;

- the possibility of normal operation and the fulfillment of design requirements during their entire service life (durability);

- the possibility of safe operation (the possibility of opening the sash without risk of falling outside) and safe maintenance (periodic cleaning).

These technical and functional requirements are very different from those for lower-rise buildings. Therefore, let us consider some of them in more detail.

\section{Features of appointment and calculation of technical characteristics of high-rise building windows}

\author{
3.1 Influence of loads and impacts on the structure of high-rise building \\ windows
}


High-rise buildings are exposed to increased values of wind loads in comparison with buildings of lower number of storeys [3-5]. For the high-rise buildings the calculated values of wind loads on the building as a whole, as well as on its individual structural elements, should be taken on the basis of wind impact modeling data in the wind tunnel and/or numerical methods. These studies should be carried out taking into account the impact of adjacent buildings. The calculation of the windows should be carried out on the peak value of the wind load. As practice shows, in many cases peak values of wind pressure due to the peculiarities of wind flow formation inside the building area are observed not only in the upper floors of the building (see figure 2).

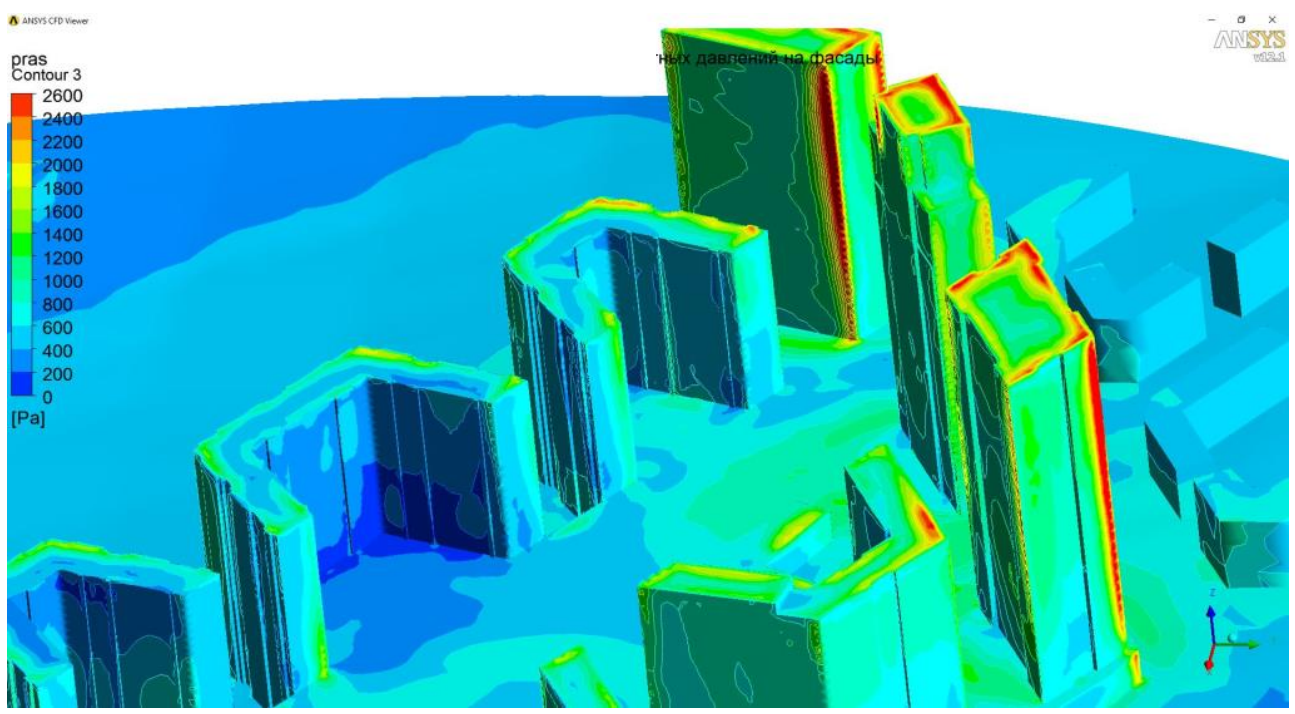

Fig. 2. The example of peak wind load calculation on the building façade

Thus, peak values of wind load in high-rise buildings can be observed also on its lower floors. This circumstance imposes the following restrictions on the process of designing high-rise buildings windows:

- the need to obtain data on the calculated wind load at the early stages of the design object for the purpose of the pre-assignment of constructive solutions windows. It is especially important when inserting PVC window frames in to the project since it is often possible to ensure the perception of peak values of wind loads only through the use of additional external amplifiers of mullion [6]. This, in turn, this can disrupt the architectural concept of the project.

- the need to differentiate the constructive solution of windows for building sections that are subject to varying impacts of wind loads, or the adoption of a single design solution for windows throughout the building based on the calculation of windows with the largest overall dimensions for the maximum value of the peak wind load acting on the building.

In the existing construction practice in the territory of the Russian Federation at glazing of high-rise buildings to a height of $75 \mathrm{~m}$, windows with a design identical to the multistorey building windows are installed. For window structures installed at a height of more than $75 \mathrm{~m}$ there are increased requirements for ensuring their safe maintenance. At the same time, it is fundamentally possible to accept only the following window constructions:

- windows with blind glazing and air valves, placed in windows or external wall;

- windows with fixed glazing and opening transom;

- windows with inward-opening sashes and a translucent protective screen located outside, with air gaps at the top and bottom; 
- windows extendable outward by 100-150 mm.

Each of these options allows the safe operation of windows. The most common solution in practice, as a rule, is the third option. In this case, the standard window must be supplemented with an external protective fence, preventing the person from falling out when the window is open in a sudden gust of wind. Taking into account the abovedescribed possibility for the formation of increased wind loads also on the high-rise building lower floors, it is obvious that it is necessary to equip the lower floor windows with a protective fence.

Insufficient amount of attention is given to the calculation and design of individual structural elements of windows. This is due to the lack of detailed requirements, as well as approved and relevant engineering methods of calculation of such elements.

In particular, the strength calculation of the window fastening elements is not considered. Currently, large-format window units are used for glazing high-rise buildings. They are exposed to significant wind loads, so the selection and calculation of fasteners of window structures should be given increased attention. At the same time, the engineering method of calculation of fastening elements for the window is not currently included in any of the current regulatory document.

This also applies to the appointment of a constructive solution openings. Very often for the device of external walls energy-efficient stone materials are currently used - foamed and sand-lime concrete, foamed polystyrene, etc. One of the disadvantages of such materials is their low bearing capacity. When erecting walls of a similar design from largeformat blocks, you need to strengthen the walls (see figure 3). This has a negative impact on the thermal characteristics of the outer wall.

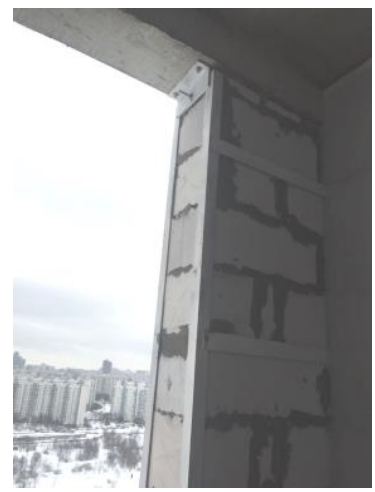

Fig. 3. The example of strengthening the walls of aerated concrete for installing a large window unit

\subsection{Air permeability}

Due to significant wind loads acting on high-rise buildings, windows in such buildings should have low air permeability. At the same time, the maximum air permeability class of the windows according to [7] corresponds to a pressure of only $600 \mathrm{~Pa}$. However, the impact of wind loads on the windows during the operation of the facility can be significantly higher, up to the peak value, and often exceed $1000 \mathrm{~Pa}$. Operating experience, as well as the results of laboratory tests of window structures used in glazing high-rise buildings shows that even with the provision of windows with defined air permeability, they still blow. This is most clearly manifested in the glazing of high-rise buildings window units of PVC profile with standard hardware (with visible hinge). In such structures already at a pressure of $600 \mathrm{~Pa}$ there is a blowing through the upper hinge of the sash, very often accompanied by an unpleasant whistle. Obviously, for high-rise residential buildings, 
which are usually structures with increased requirements for comfort and safety, such phenomena are unacceptable.

\subsection{Water permeability}

It is obvious that for high-rise buildings exposed to significant wind loads, in the conditions of a shower, the key is the lack of window leakage. This issue is currently not sufficiently studied. Only a limited number of studies have been carried out to justify the initial data for the calculation of the windows water permeability, as well as methods for calculating the windows water permeability [8-13]. Therefore, in practice, only windows water permeability laboratory methods of testing are currently used.

\section{Laboratory tests of high-rise building windows}

As noted earlier, for windows of high-rise buildings one of the main factors affecting their construction is the wind load. At present, a simplified engineering method is used to calculate wind loads on windows. Studies show that it has a significant reserve both in strength and in rigidity, and does not take into account the joint work of structural elements of window units $[14,15]$. At the same time, it does not take into account the construction features of modern window units. Therefore, for window units of high-rise buildings it is advisable to conduct laboratory tests on the effect of wind loads (see figure 4) on window structures. These tests will allow not only to confirm the compliance of the adopted construction of units with the requirements of existing regulations, but also to check the correctness when selecting their equipment (window hardware, seals) to avoid blowing and leakage of the structure. Laboratory tests on the wind load allow to check the operability of the window after the cyclic impact of the wind load, and to simulate the effect of the wind load on its main operational characteristics during the life cycle of the window.

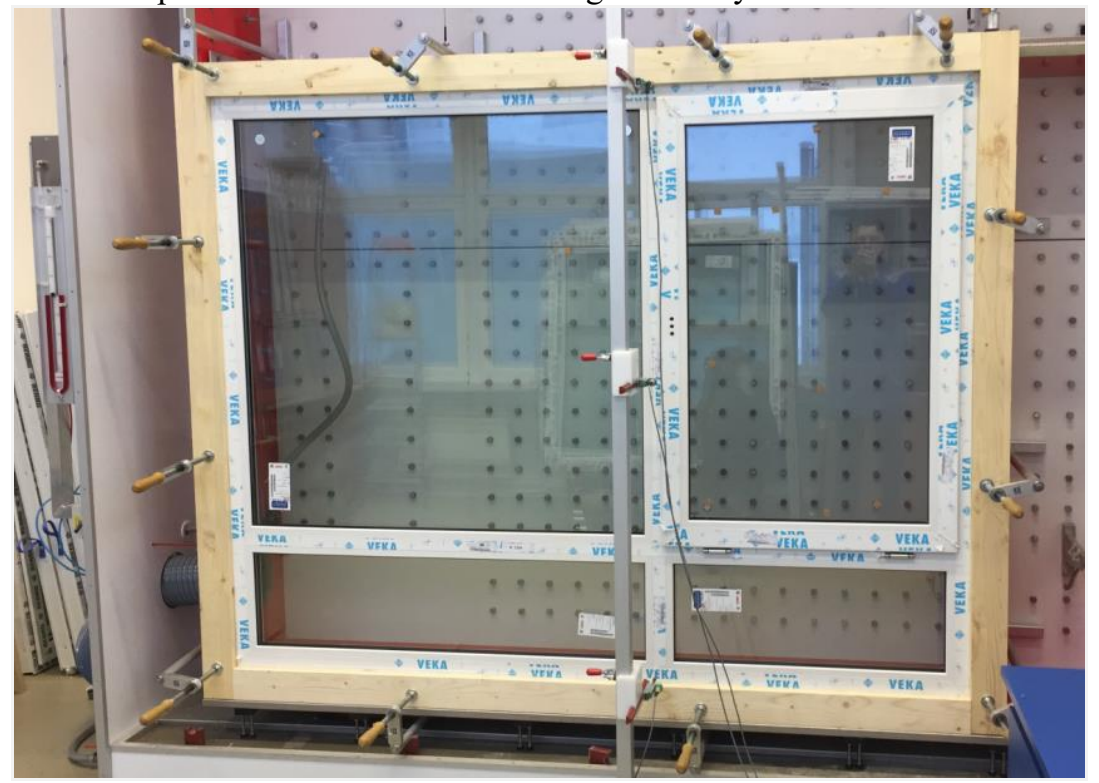

Fig. 4. The appearance of the laboratory stand with the installed sample of a large-format window unit of a high-rise building for testing the resistance to wind loads, air- and water permeability 


\section{Discussion}

It is obvious that the question of design and calculation of windows of high-rise buildings should be approached responsibly. This issue needs to be addressed in a comprehensive manner.

Currently, the design of high-rise building windows as well as most scientific research aimed at finding the optimal design solutions and orientation of windows in terms of energy efficiency (heating / air conditioning, lighting) and creating a comfortable microclimate (i.e. taking into account both thermal and optical window characteristics, their air permeability, natural ventilation) [16-21].

Much less research is devoted to the study of reliability and specificity of high-rise building windows operation (for example, window cleaning [22] or the possibility of windows destruction by debris in a hurricane [23]).

Such structures should have increased requirements, especially in terms of ensuring their operational safety and tightness. Even now, when designing windows of high-rise buildings, along with engineering methods for calculating their basic characteristics (heat transfer resistance, light transmission, etc.), laboratory methods for determining the compliance of the actual characteristics of windows with the requirements of the project should also be used. Each high-rise building is unique, so it is hardly possible to refuse to conduct such tests in the future. However, the following promising areas of research will streamline the process of designing windows of high-rise buildings. They will increase operational reliability, as well as reduce the cost of their manufacture:

-justification of calculated values of operational loads on window blocks of high-rise buildings;

- development of calculation models and engineering methods for strength calculation of window units and their individual elements, taking into account the design features of their devices.

\section{Conclusions}

In this work the existing approach for designing and calculating windows of high-rise buildings was considered. It is established that the existing approach based on the existing normative regulations is not an integrated approach, because only the individual structural elements of the window are subjected to calculation and design. This leads to a number of typical problems at the stage of installation and operation of window structures. So now, appointment of the constructive solution of windows of high-rise buildings should be made taking into account their laboratory tests on resistance to wind loads, air permeability and water permeability, since engineering methods for calculating these characteristics have not yet been developed.

\section{References}

1. I. Boriskina I V Buildings and Structures with Translucent Facades and Roofs. Theoretical Bases of Designing of Glass Constructions (2012)

2. I. Boriskina, A. Plotnikov, A. Zaharov, Design of modern window systems for civil buildings (2008)

3. E. Gavanski, G. Kopp, Journal of Architectural Engineering 17(1), pp 34-41 (2011)

4. M. Mikhaylova, V. Dalinchuk, A. Bushmanova, L. Dobrogorskaya, Construction of Unique Buildings and Structures 10, pp 59-74 (2016) 
5. A. Povzun, N. Buzun, S. Zimin, Construction of Unique Buildings and Structures 3(30), pp70-80 (2015)

6. A. Konstantinov, L. Ratnayake, E3S Web of Conferences 33, 02025 (2018)

7. DIN EN 14351-1:2016-12 Windows and doors - Product standard, performance characteristics - Part 1: Windows and external pedestrian doorsets; German version EN 14351-1:2006+A2:2016 (2016)

8. C. Lopez, F.J. Masters, S. Bolton Building and Environment 46(7), pp 1329-1342 (2011)

9. B. Blocken, J. Carmeliet Journal of Wind Engineering and Industrial Aerodynamics 92 (13), pp 1079-1130 (2004)

10. E.C.C. Choi Journal of Wind Engineering and Industrial Aerodynamics 51(1), pp. 5569 (1994)

11. S.M. Cornick, M.A. Lacasse Journal of ASTM International 2(10), pp 183-198 (2005)

12. C.T. Salzano, F.J. Masters, J.D. Katsaros Building and Environment 45(6), pp 13731388 (2010)

13. N. Van Den Bossche, A. Janssens Building and Environment 110, pp129-139 (2016)

14. A.P. Konstantinov, Science prospects, 1(100), pp 26-31 (2018)

15. A. Konstantinov, M. Motina, IOP Conf. Series: Materials Science and Engineering, 463, 032044 (2018)

16. Y. Yaşar, S.M. Kalfa Energy Conversion and Management 64, pp 170-181 (2012)

17. G. Hong, B.S. Kim Building and Environment 97, pp 48-54 (2016)

18. J. Cho, C. Yoo, Y. Kim Journal of Asian Architecture and Building Engineering 11(2), pp 391-398 (2012)

19. R.A. Mangkuto, M. Rohmah, A.D. Asri Applied Energy 164, pp 211-219 (2016)

20. M.B.C. Aries, E.J. Van Loenen, J.L.M. Hensen Applied Energy 95, pp 238-245 (2012)

21. M.A. Hassan, N.M. Guirguis, M.R. Shaalan, K.M. El-Shazly Desalination 209 (1-3 SPEC. ISS.), pp 251-260 (2007)

22. B.-L. Chen Applied Mechanics and Materials 584-586, pp 780-783 (2014)

23. F.J. Masters, K.R. Gurley, N. Shah, G. Fernandez Engineering Structures 32 (4), pp 911-921 (2010) 